\title{
BMJ Open Pregnancy history and current use of contraception among women of reproductive age in Burundi, Kenya, Rwanda, Tanzania and Uganda: analysis of demographic and health survey data
}

\author{
Pauline Bakibinga, ${ }^{1}$ Dennis J Matanda, ${ }^{2}$ Rogers Ayiko, ${ }^{3}$ Joseph Rujumba, ${ }^{4}$ \\ Charles Muiruri, ${ }^{5}$ Djesika Amendah, ${ }^{1}$ Martin Atela ${ }^{6}$
}

To cite: Bakibinga $P$, Matanda DJ, Ayiko R, et al. Pregnancy history and current use of contraception among women

of reproductive age in Burundi, Kenya, Rwanda, Tanzania and Uganda: analysis of demographic and health survey data. BMJ Open 2016;6:e009991.

doi:10.1136/bmjopen-2015009991

- Prepublication history for this paper is available online. To view these files please visit the journal online (http://dx.doi.org/10.1136/ bmjopen-2015-009991).

Received 14 September 2015 Revised 9 February 2016 Accepted 19 February 2016

CrossMark

For numbered affiliations see end of article.

Correspondence to Dr Pauline Bakibinga; paulabak80@gmail.com

\section{ABSTRACT}

Objective: To examine the relationship between pregnancy history and the use of contraception among women of reproductive age (15-49 years) in East Africa.

Methods: Demographic and Health Surveys data from Burundi (2010), Kenya (2008-2009), Rwanda (2010), Tanzania (2010) and Uganda (2011) were used in the analysis. Logistic regression was used to determine the effects of women's pregnancy history on their use of contraception.

Setting: Burundi, Kenya, Rwanda, Tanzania and Uganda.

Participants: 3226, 2377, 4396, 3250 and 2596 women of reproductive age (15-49 years) from Burundi, Kenya, Rwanda, Tanzania and Uganda, respectively, were included in the analysis.

Results: Women who had experienced a mistimed pregnancy were more likely to use a modern contraceptive method during their most recent sexual encounter in Kenya, Rwanda, Burundi and Uganda. Other significant correlates of women's contraceptive use were: desire for more children, parity, household wealth, maternal education and access information through radio. In-country regional differences on use of modern contraceptive methods were noted across five East African countries.

Conclusions: Women's birth histories were significantly associated with their decision to adopt a modern contraceptive method. This highlights the importance of considering women's birth histories, especially women with mistimed births, in the promotion of contraceptive use in East Africa. Variations as a result of place of residency, educational attainment, access to family planning information and products, and wealth ought to be addressed in efforts to increase use of modern contraceptive methods in the East African region.

\section{Strengths and limitations of this study}

- A major strength of this study is the use of nationally representative samples in five East African countries to study the influence of women's birth history on their contraceptive use.

- The study has affirmed the importance of considering women's birth histories in the promotion of contraceptive use in the East African region.

- The study did not control for an important variable relating to decision-making on contraceptive use as there were many missing cases.

- Like any cross-sectional study, interpretations are limited to associations rather than causal relationships of the determinants of contraceptive use.

\section{INTRODUCTION}

In the past two decades, sub-Saharan Africa has experienced significant increases in contraceptive knowledge and prevalence. The five East African countries-Burundi, Kenya, Rwanda, United Republic of Tanzania and Uganda-witnessed unprecedented progress in reproductive, maternal, newborn and child health (RMNCH). For example, contraceptive prevalence rates have, over the years, increased significantly in Rwanda from $21.2 \%$ in 1992 to $51.6 \%$ in $2011,{ }^{1}$ and in Kenya from $32.7 \%$ in 1993 to $58 \%$ in $2014 .^{2}$ In Uganda, maternal mortality reduced from 604 to $310 / 100000$ live births in the period between 2000 and 2013 owing to the accelerated Millennium Development Goals framework. ${ }^{3}$ Similarly, Burundi recorded notable declines in infant and under-five mortality from $110 / 1000$ in 1990 to $86 / 1000$ in 2011 
and from $183 / 1000$ in 1990 to $139 / 1000$ in 2011, respectively. ${ }^{4}$ In Tanzania, facility-based deliveries increased from $44 \%$ in 1999 to $51 \%$ in $2010 .^{56}$

Despite this overall progress, evidence suggests that the East African Community (EAC) region is still grappling with major gaps in access and quality in RMNCH services. ${ }^{7}$ Even though contraceptive knowledge is nearly universal in the region and contraceptive prevalence has increased in the past two decades, the unmet need for contraception remains high in all the countries (table 1). Whereas proven strategies to reduce unplanned pregnancy such as increasing access to and correct use of effective contraception and contraceptive counselling exist, on average, only $46 \%$ of all sexually active women who would want to use contraceptives in East Africa in 2012 could access them. ${ }^{89}$

Research has documented an association between contraceptive use and unplanned pregnancy in some settings. ${ }^{10-13}$ Poor use of short-term hormonal contraceptive methods are known to be responsible for a high proportion of unintended pregnancies. ${ }^{11}$ Other predictors of unplanned childbearing are residence, ethnicity, marital status, low maternal education and maternal age. ${ }^{12}$ Moreover, a history of an unplanned pregnancy predicts the future occurrence of another unplanned pregnancy. ${ }^{14}$ However, research on the links between the maternal history of an unplanned pregnancy and current use of contraception in East Africa is limited. ${ }^{15-17}$ Most of the evidence is based on studies from Western contexts. ${ }^{15}{ }^{16}$ Matteson $e t a l^{15}$ demonstrated that a past experience of an unplanned pregnancy did not predict overall contraceptive use among young women aged $14-25$ years in the USA. In contrast, a recent study conducted in the urban slums of Kenya indicated that women whose last pregnancy was unintended were more likely to be using a modern method of contraception, compared to their counterparts whose last pregnancy was intended. ${ }^{17}$ The study found marked variations among these groups of women driven by their socioeconomic status: unintended pregnancy was not associated with subsequent contraceptive use among poor women, unlike among wealthier women. However, the generalisation of this study's findings to other settings in Kenya or in the region is limited, given that the study was done among urban poor women. Additionally, the small sample size of the study limited the understanding of the issues to the urban setting. These limitations should be addressed if the linkages between unplanned pregnancy and current or future use of contraception among the general population in the East African region and other regions with similar context are to be better understood.

This paper attempts to address this gap by using nationally representative samples to examine the relationship between pregnancy history and subsequent use of contraception among women aged 15-49 years in the five East African partner states.

\section{Context}

In 2013, the EAC, consisting of Burundi, Kenya, Rwanda, Tanzania and Uganda, was home to approximately 143.5 million residents, with an annual population growth rate of $2.9 \% .^{18}$ In the same period, the regional average maternal mortality rate stood at 469/100 000 live births, infant mortality was $62 / 1000$ live births and child mortality at 98/1000 live births. These data, considered in the light of the high total fertility rate of $5.2 \%$, and a generally high HIV prevalence among partner states (Kenya $6 \%$, Rwanda 3\%, Tanzania 5\%, and Uganda 7\%), point to gaps in the knowledge and use of reproductive health information, especially gaps in access to and proper use of contraception. This is particularly so given that evidence points to the benefits of contraception such as reduced infant, maternal and child mortality and prevention/reduction of unwanted pregnancies that often lead to unsafe abortion. ${ }^{19-21}$ This context, together with the fact that the EAC partner states are increasingly cooperating in health through collaborative determination of health priorities and implementation of common policies, strategies, plans and investments, makes the region a unique context for investigating issues of unintended pregnancy and contraceptive use among women of reproductive age.

\section{METHODS}

\section{Data sources}

The study used data from the most recent Demographic and Health Surveys (DHS) in Burundi, Kenya, Tanzania, Rwanda and Uganda. DHS are a series of nationally representative data collected by the respective countries and cover the areas of demography, health and family planning (FP). The surveys are implemented by the respective countries' governments in collaboration with development partners and with technical assistance from ICF International. The data sets are freely available to the

\begin{tabular}{lllll} 
Table 1 & Selected reproductive health indicators in Burundi, Kenya, Rwanda, Tanzania and Uganda & 1-4 6 \\
\hline & $\begin{array}{l}\text { Contraceptive prevalence } \\
\text { (any method, \%) }\end{array}$ & $\begin{array}{l}\text { Total fertility } \\
\text { rate (\%) }\end{array}$ & $\begin{array}{l}\text { Unmet need for } \\
\text { family planning (\%) }\end{array}$ & $\begin{array}{l}\text { Knowledge of contraceptive } \\
\text { methods (any method, \%) }\end{array}$ \\
\hline Burundi & 21.9 & 6.4 & 31.0 & 99.2 \\
Kenya & 45.5 & 4.6 & 25.6 & 95 \\
Rwanda & 51.6 & 4.6 & 18.9 & 99.3 \\
Tanzania & 34.4 & 5.4 & 25.3 & 98 \\
Uganda & 30.0 & 6.2 & 34.3 & 98.2 \\
\hline
\end{tabular}


public on application to MEASURE DHS and require no further ethical clearance. At the time of our analysis and write-up, Kenya had released preliminary DHS results for 2014, but the data had not been released.

DHS use a household questionnaire to enlist all members and visitors who spent the previous night in the selected households to capture basic demographic data such as age, sex, education and relationship to the head of the household. The household questionnaire also collects information on household characteristics such as source of drinking water, type of toilet facility and the type of material used for house construction. The rationale for data collection on all members and visitors in the household is to identify women and men eligible for the individual interview.

The woman's questionnaire captures the respondent's background characteristics (age, education and media exposure); birth history and childhood mortality; knowledge and use of FP methods; fertility preferences; antenatal, delivery and postnatal care; breastfeeding and infant feeding practices; vaccinations and childhood illnesses; marriage and sexual activity. It also gathers data on a woman's work and her husband's background characteristics; her awareness and behaviour regarding Acquired Immune Deficiency Syndrome (AIDS) and other sexually transmitted infections in addition to adult mortality, including maternal mortality, knowledge of tuberculosis; and gender-based violence. The man's questionnaire collects information similar to that in the woman's questionnaire except for questions on reproductive history and maternal and child health.
The surveys utilise a two-stage sampling strategy-clusters are first selected from the most recent population census sample frame and later, and households are systematically selected from the clusters. Participants eligible for interview include all women of ages 15-49 years and men of ages 15-54 years who are either permanent residents of the selected household or are visitors who spent a night in the household before the survey. To facilitate data collection at household and individual levels, the surveys use model questionnaires developed by the MEASURE DHS programme developed specifically for households, women and men. These questionnaires undergo slight modifications at country level to reflect demographic and health issues relevant to respective countries. Detailed information about sampling strategies and data collection can be found in the DHS reports for respective countries. ${ }^{1-46}$ Samples used in this study are presented in table 2 and refer to women of ages 15-49 years who were not pregnant during the survey, had sex intercourse at least once in the month preceding the survey and had at least one birth.

\section{Variables}

Contraceptive use, which was the dependent variable, was coded zero $(0)$ if the woman used a modern contraceptive method (pill, intrauterine device, injections, condoms, female sterilisation and Norplant) and one (1) if she used a non-modern method (folkloric and traditional methods) or did not use any method during the most recent sexual encounter. The main independent variable was pregnancy history whereby the last

\begin{tabular}{|c|c|c|c|c|c|c|c|c|c|c|}
\hline \multirow[b]{2}{*}{ Variables } & \multicolumn{2}{|c|}{ Kenya (2008-2009) } & \multicolumn{2}{|c|}{ Uganda (2011) } & \multicolumn{2}{|c|}{ Tanzania (2010) } & \multicolumn{2}{|c|}{ Rwanda (2010) } & \multicolumn{2}{|c|}{ Burundi (2010) } \\
\hline & Per cent & $\mathbf{n}$ & Per cent & $\mathbf{n}$ & Per cent & $\mathbf{n}$ & Per cent & $\mathbf{n}$ & Per cent & $\mathbf{n}$ \\
\hline Total sample & 100.0 & 2377 & 100.0 & 2596 & 100.0 & 3250 & 100.0 & 4396 & 100.0 & 3226 \\
\hline \multicolumn{11}{|l|}{ Contraceptive use } \\
\hline Modern & 51.0 & 1113 & 37.0 & 941 & 42.5 & 1280 & 58.0 & 2578 & 25.5 & 856 \\
\hline No/non-modern & 49.0 & 1264 & 63.0 & 1655 & 57.5 & 1970 & 42.0 & 1818 & 74.5 & 2370 \\
\hline \multicolumn{11}{|l|}{ Pregnancy history } \\
\hline Wanted & 56.5 & 1467 & 52.2 & 1405 & 72.1 & 2354 & 58.9 & 2587 & 65.6 & 2130 \\
\hline Mistimed & 25.1 & 543 & 34.3 & 861 & 23.4 & 757 & 26.3 & 1153 & 28.1 & 888 \\
\hline Unwanted & 18.4 & 367 & 13.5 & 330 & 4.5 & 139 & 14.8 & 656 & 6.3 & 208 \\
\hline \multicolumn{11}{|l|}{ Maternal age } \\
\hline $15-19$ & 4.4 & 123 & 5.5 & 153 & 5.0 & 141 & 1.1 & 47 & 2.5 & 77 \\
\hline $20-29$ & 53.0 & 1249 & 51.6 & 1348 & 48.7 & 1510 & 45.8 & 2008 & 47.5 & 1489 \\
\hline $30-39$ & 34.4 & 807 & 32.6 & 845 & 36.3 & 1179 & 39.2 & 1740 & 36.1 & 1205 \\
\hline $40-49$ & 8.1 & 198 & 10.3 & 250 & 10.0 & 420 & 13.9 & 601 & 14.0 & 455 \\
\hline \multicolumn{11}{|l|}{ Residence } \\
\hline Urban & 22.1 & 658 & 16.6 & 625 & 24.6 & 731 & 12.1 & 605 & 8.4 & 585 \\
\hline Rural & 77.9 & 1719 & 83.4 & 1951 & 75.4 & 2519 & 87.9 & 3791 & 91.6 & 2641 \\
\hline \multicolumn{11}{|l|}{ Maternal education } \\
\hline Higher & 5.7 & 167 & 4.3 & 141 & 0.4 & 13 & 1.2 & 65 & 0.7 & 46 \\
\hline Secondary & 22.1 & 461 & 19.6 & 516 & 7.2 & 409 & 8.4 & 391 & 6.2 & 305 \\
\hline Primary & 63.4 & 1344 & 62.5 & 1533 & 70.1 & 2089 & 72.2 & 3156 & 40.9 & 1304 \\
\hline No education & 8.8 & 405 & 13.6 & 406 & 22.3 & 739 & 28.2 & 784 & 52.2 & 1571 \\
\hline
\end{tabular}


pregnancy was categorised as wanted, mistimed or unwanted. In this analysis, wanted pregnancies refer to pregnancies that were planned at conception or reported to have happened at the 'right time' or later than desired (because of infertility or difficulties in conceiving). Mistimed pregnancies are those that occurred earlier than desired while unwanted pregnancies are pregnancies that were reported to have occurred when no children, or no more children, were desired.

Other independent variables were grouped into three categories: individual, household and community. Individual variables included maternal age (15-19, 2029, 30-39 or 40-49 years), woman's desire for more children (want more or want no more), and maternal parity (treated as a continuous variable). Household variables included maternal educational attainment (no education, primary, secondary or higher education), household quintile of wealth (poorest, poor, middle, rich, richer or richest), religion (Christian, Muslim or other religion), media exposure at least once in a week through radio, television or newspaper/magazine (yes or no), and woman's decision-making on her healthcare (makes decisions alone or not alone). Finally, Community variables consisted of a woman's place of residence (urban or rural), region (geographical/ administrative boundaries in the respective countries), and whether a woman had been visited by a FP worker in the past few months (yes or no).

\section{Analysis}

All statistical analyses were conducted using IBM SPSS Statistics V.22. To account for the multistage sampling strategy adopted by DHS in the respective country surveys, the study used the SPSS Complex Samples Module to incorporate sample weights, primary sampling unit (clusters) and sample domain (strata) in all the analyses. ${ }^{22}$ Logistic regression was used to first determine the raw effects of maternal pregnancy history in predicting contraceptive use among sexually active women (table 3 ). In the second stage, other individual level variables were included in the regression model to determine the gross effects of maternal pregnancy history in predicting contraceptive use (table 4). Table 5 shows the gross effects of maternal pregnancy history in predicting contraceptive use, taking into account variables at the individual and household levels. The last stage of the analysis (table 6) shows the net effects of pregnancy history in predicting contraceptive use taking into account variables at a woman's individual, household and community level.

\section{RESULTS}

\section{Descriptive statistics}

Table 2 summarises sample characteristics of the five East African countries. Across the region, women in Burundi had the lowest prevalence in the use of modern contraceptive methods $(25 \%)$ with the majority $(75 \%)$ either using folkloric, traditional or no contraceptive method during their most recent sexual encounter. Rwanda had the highest prevalence of modern contraceptive use $(58 \%)$. In relation to pregnancy history, unwanted pregnancies were highest in Kenya (18\%) while mistimed pregnancies were highest in Uganda (34\%). Of the sampled populations, the majority of women across the five countries were aged between 20 and 29 years, resided in rural areas and had attained primary education.

\section{LOGISTIC REGRESSION RESULTS}

Table 3 shows unadjusted associations between contraceptive use and maternal pregnancy history of the five East African countries. Results indicate that maternal pregnancy history was a significant predictor of contraceptive use among sexually active women in Uganda (OR 0.80, $\mathrm{p}<0.05$ ), Tanzania (OR 0.58, $\mathrm{p}<0.01$ ), Rwanda (OR 0.84, $\mathrm{p}<0.05$ ) and Burundi (OR 0.67, $\mathrm{p}<0.001$ ), but not in Kenya.

Results of adjusted regression models are shown in tables 4-6. Adjusting for other individual, household and community variables, maternal pregnancy history persisted as a significant predictor of contraceptive use in Uganda, Rwanda and Burundi and becomes significant in Kenya. Women who had a mistimed pregnancy history were less likely to use a non-modern contraceptive method or none at all during their most recent sexual encounter as compared to those who had a wanted pregnancy history in Kenya (OR $0.67,0.50$ to 0.90 ), Rwanda (OR 0.84, 0.73 to 0.97) and Burundi (OR $0.75,0.60$ to 0.94$)$. In Uganda, women who had experienced either a mistimed (OR $0.72,0.58$ to 0.90 ) or unwanted (OR $0.67,0.47$ to 0.97 ) pregnancy were less likely to use a non-modern contraceptive method or none at all during their most recent sexual encounter.

At the individual level, a woman's desire for more children persisted across all the five countries even after controlling for household and community variables.

Table 3 Logit models with maternal pregnancy history as the sole correlate of contraceptive use

\begin{tabular}{|c|c|}
\hline Kenya (2008-2009) & Uganda (2011) \\
\hline $95 \% \mathrm{Cl}$ & $\overline{\text { OR }}$ \\
\hline
\end{tabular}

\begin{tabular}{|c|c|c|c|c|c|c|c|c|c|c|}
\hline \multicolumn{11}{|c|}{ Pregnancy history: wanted (ref) } \\
\hline Mistimed & 0.77 & 0.60 to 1.00 & $0.80^{*}$ & 0.66 to 0.97 & 0.95 & 0.77 to 1.16 & $0.84^{\star}$ & 0.73 to 0.97 & $0.67^{\star \star \star}$ & 0.55 to 0.83 \\
\hline Unwanted & 1.01 & 0.74 to 1.38 & 0.73 & 0.53 to 1.00 & $0.58^{\star \star}$ & 0.38 to 0.88 & 1.12 & 0.94 to 1.33 & 0.87 & 0.61 to 1.25 \\
\hline
\end{tabular}




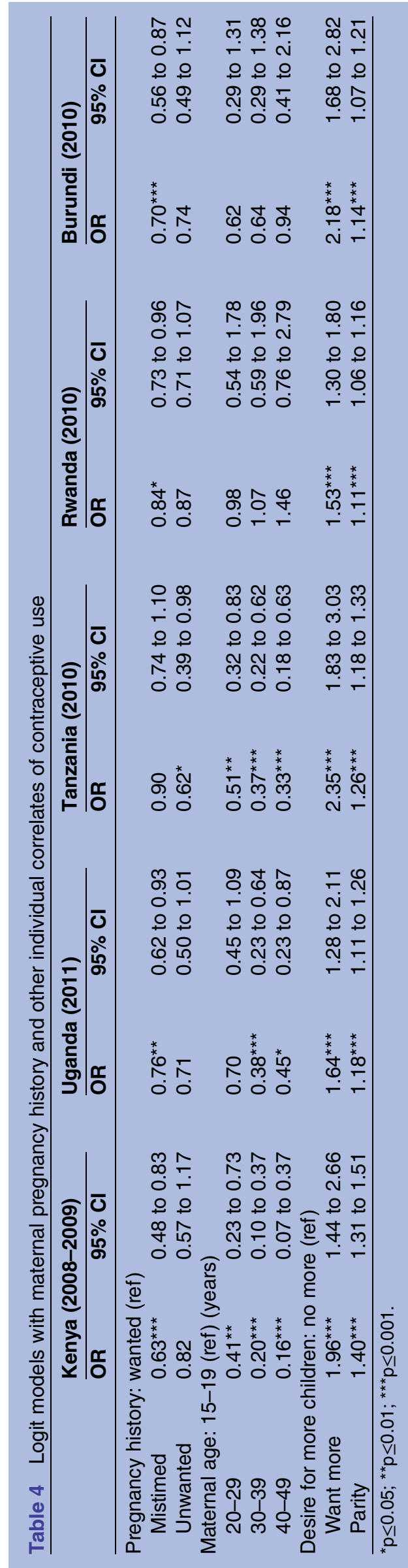

Women who desired more children had higher odds of using a non-modern contraceptive method or none at all as compared to those who did not want more children in all countries and the ORs were quite similar. Maternal parity persisted only in Kenya (OR 1.20, 1.20 to 1.32) and Rwanda (OR 1.09, 1.04 to 1.14) after introduction of community level variables; an increase in the number of births was associated with an increase in the probability of using no/non-modern contraceptive method. Maternal age was a significant predictor of contraceptive use at the individual level of the analysis but faded when household and community level variables were controlled for.

At a household level, wealth was a consistent predictor of contraceptive use across all the five member states of the East African region, taking into account other variables at the three levels of analysis. Compared to their counterparts in the richest wealth quartile, women belonging to the poorest wealth quintile were twice as likely to use a non-modern contraceptive method or none at all in Uganda (OR 2.74, 1.73 to 4.33), Kenya (OR 2.16, 1.28 to 3.66) and Tanzania (OR 2.05, 1.24 to 3.39). The ORs were lower in Burundi (OR 1.56, 1.06 to 2.31) and Rwanda (OR 1.51, 1.14 to 2.01). Maternal educational attainment persisted as a predictor of contraceptive use in Uganda, Tanzania and Rwanda after introduction of community level variables. In Uganda and Rwanda, women with no education were almost three times more likely (OR 2.89, 1.60 to 5.22 and OR $2.73,1.33$ to 5.60 , respectively) to use a nonmodern contraceptive method or none at all than those who had attained higher education. However, the case was different in Tanzania where women who had no education were less likely to use a non-modern contraceptive method or none at all during their most recent sexual encounter (OR $0.10,0.02$ to 0.58 ).

Other household variables that persisted as predictors of contraceptive use after adjusting for community variables were women's access to FP information through radio and religion. Having not heard about FP through radio was associated with higher odds of using a nonmodern contraceptive method or none at all in Kenya (OR 1.35, 1.03 to 1.77), Tanzania (OR 1.38, 1.09 to 1.74) and Rwanda (OR 1.27, 1.10 to 1.48). Not being Christian or Muslim was associated with higher odds of using a non-modern contraceptive method or none at all in Kenya (OR 2.82, 1.18 to 6.74) while the contrast was true in Burundi (OR 0.51, 0.31 to 0.86 ) where it was associated with less likelihood of using no/non-modern contraceptive.

Turning to community level variables, significant in-country regional differences were observed in Kenya, Tanzania, Rwanda and Burundi after adjusting for other variables at the individual, household and community levels. In Kenya, women residing in the North Eastern region were three times more likely to engage in sex (OR $3.35,1.15$ to 9.74$)$ using either no contraceptive or a non-modern contraceptive as compared to those residing 
Table 5 Logit models with maternal pregnancy history and other individual and household correlates of contraceptive use

\begin{tabular}{|c|c|c|c|c|c|c|c|c|c|c|}
\hline & \multicolumn{2}{|c|}{ Kenya (2008-2009) } & \multicolumn{2}{|c|}{ Uganda (2011) } & \multicolumn{2}{|c|}{ Tanzania (2010) } & \multicolumn{2}{|c|}{ Rwanda (2010) } & \multicolumn{2}{|c|}{ Burundi (2010) } \\
\hline & $\overline{\text { OR }}$ & $95 \% \mathrm{Cl}$ & $\overline{\text { OR }}$ & $95 \% \mathrm{Cl}$ & $\overline{\text { OR }}$ & $95 \% \mathrm{Cl}$ & $\overline{\text { OR }}$ & $95 \% \mathrm{Cl}$ & $\overline{\text { OR }}$ & $95 \% \mathrm{Cl}$ \\
\hline \multicolumn{11}{|c|}{ Pregnancy history: wanted (ref) } \\
\hline Mistimed & $0.66^{\star \star}$ & 0.49 to 0.87 & $0.72^{\star *}$ & 0.58 to 0.89 & 0.95 & 0.76 to 1.19 & $0.83^{*}$ & 0.72 to 0.96 & $0.72^{* *}$ & 0.58 to 0.90 \\
\hline Unwanted & 0.90 & 0.59 to 1.36 & $0.68^{\star}$ & 0.48 to 0.98 & 0.69 & 0.41 to 1.16 & 0.85 & 0.68 to 1.06 & 0.79 & 0.51 to 1.21 \\
\hline \multicolumn{11}{|c|}{ Maternal age: 15-19 (ref) (years) } \\
\hline $20-29$ & 0.58 & 0.33 to 1.03 & 0.85 & 0.52 to 1.40 & $0.53^{*}$ & 0.31 to 0.91 & 0.98 & 0.52 to 1.84 & 0.68 & 0.30 to 1.53 \\
\hline 30-39 & $0.38^{* *}$ & 0.19 to 0.75 & 0.62 & 0.35 to 1.12 & $0.40^{\star *}$ & 0.22 to 0.74 & 1.13 & 0.60 to 2.15 & 0.82 & 0.35 to 1.92 \\
\hline $40-49$ & $0.38^{\star}$ & 0.16 to 0.91 & 0.76 & 0.37 to 1.53 & $0.39^{\star \star}$ & 0.19 to 0.79 & 1.63 & 0.82 to 3.24 & 1.15 & 0.46 to 2.90 \\
\hline \multicolumn{11}{|c|}{ Desire for more children: no more (ref) } \\
\hline Want more & $1.70^{\star \star \star}$ & 1.24 to 2.33 & $1.58^{\star \star \star}$ & 1.22 to 2.06 & $2.12^{\star \star \star}$ & 1.60 to 2.81 & $1.51^{\star \star \star}$ & 1.28 to 1.79 & $1.99^{\star \star \star}$ & 1.53 to 2.60 \\
\hline Parity & $1.23^{\star \star *}$ & 1.13 to 1.35 & 1.05 & 0.98 to 1.12 & $1.18^{* * *}$ & 1.11 to 1.26 & $1.10^{\star * *}$ & 1.05 to 1.15 & $1.09^{*}$ & 1.02 to 1.17 \\
\hline \multicolumn{11}{|c|}{ Maternal education: higher (ref) } \\
\hline Secondary & 0.80 & 0.47 to 1.37 & 1.36 & 0.85 to 2.17 & $0.07^{\star \star}$ & 0.01 to 0.43 & 1.85 & 0.94 to 3.65 & 0.80 & 0.36 to 1.79 \\
\hline Primary & 1.04 & 0.60 to 1.82 & $1.78^{*}$ & 1.09 to 2.89 & $0.06^{\star \star}$ & 0.01 to 0.39 & $2.36^{\star}$ & 1.19 to 4.68 & 1.10 & 0.47 to 2.58 \\
\hline No education & 1.28 & 0.56 to 2.91 & $2.99^{\star \star \star}$ & 1.67 to 5.36 & $0.09^{\star \star}$ & 0.01 to 0.51 & $2.82^{* *}$ & 1.39 to 5.72 & 1.32 & 0.56 to 3.13 \\
\hline \multicolumn{11}{|c|}{ Wealth index: richest (ref) } \\
\hline Rich & 1.06 & 0.72 to 1.55 & 1.23 & 0.90 to 1.70 & 0.86 & 0.61 to 1.22 & 0.93 & 0.73 to 1.20 & 1.16 & 0.82 to 1.66 \\
\hline Middle & 1.09 & 0.75 to 1.55 & $1.58^{*}$ & 1.09 to 2.28 & $1.55^{\star}$ & 1.10 to 2.17 & 0.95 & 0.74 to 1.24 & 1.17 & 0.84 to 1.62 \\
\hline Poor & 1.26 & 0.85 to 1.85 & $1.67^{\star \star}$ & 1.16 to 2.41 & 1.34 & 0.92 to 1.97 & $1.34^{*}$ & 1.04 to 1.73 & 1.30 & 0.92 to 1.83 \\
\hline Poorest & $2.88^{\star \star \star}$ & 1.86 to 4.44 & $2.83^{\star \star \star}$ & 1.91 to 4.18 & $1.60^{*}$ & 1.08 to 2.38 & $1.47^{\star *}$ & 1.13 to 1.91 & $1.48^{*}$ & 1.05 to 2.09 \\
\hline \multicolumn{11}{|c|}{ Religion: Christian (ref) } \\
\hline Muslim & $1.62^{*}$ & 1.02 to 2.58 & 1.25 & 0.88 to 1.78 & NA & NA & 0.73 & 0.38 to 1.40 & 0.63 & 0.38 to 1.03 \\
\hline Other & $2.49^{\star}$ & 1.05 to 5.90 & 1.86 & 0.70 to 4.93 & NA & NA & 0.77 & 0.46 to 1.28 & $0.40^{\star \star \star}$ & 0.24 to 0.68 \\
\hline \multicolumn{11}{|c|}{ Listened to radio: yes (ref) } \\
\hline No & $1.45^{\star *}$ & 1.11 to 1.90 & 1.12 & 0.87 to 1.45 & 1.22 & 0.98 to 1.53 & $1.31^{\star * *}$ & 1.13 to 1.52 & $1.28^{* *}$ & 1.04 to 1.58 \\
\hline \multicolumn{11}{|c|}{ Watched TV: yes (ref) } \\
\hline No & 1.64 & 0.98 to 2.76 & 1.26 & 0.90 to 1.76 & 1.22 & 0.85 to 1.75 & 0.78 & 0.55 to 1.11 & $2.20^{\star *}$ & 1.32 to 3.66 \\
\hline \multicolumn{11}{|c|}{ Read newspaper: yes (ref) } \\
\hline No & 0.97 & 0.68 to 1.37 & 1.38 & 0.98 to 1.94 & 1.19 & 0.88 to 1.62 & 1.07 & 0.72 to 1.58 & 1.18 & 0.70 to 1.99 \\
\hline \multicolumn{11}{|c|}{ Healthcare decision-making: alone (ref) } \\
\hline Not alone & 1.06 & 0.81 to 1.40 & 1.02 & 0.80 to 1.30 & 0.92 & 0.69 to 1.22 & $1.30^{\star *}$ & 1.09 to 1.55 & 0.81 & 0.57 to 1.15 \\
\hline
\end{tabular}




\begin{tabular}{|c|c|c|c|c|c|c|c|c|c|c|}
\hline & \multicolumn{2}{|c|}{ Kenya (2008-2009) } & \multicolumn{2}{|c|}{ Uganda (2011) } & \multicolumn{2}{|c|}{ Tanzania (2010) } & \multicolumn{2}{|c|}{ Rwanda (2010) } & \multicolumn{2}{|c|}{ Burundi (2010) } \\
\hline & $\overline{\text { OR }}$ & $95 \% \mathrm{Cl}$ & $\overline{\text { OR }}$ & $95 \% \mathrm{Cl}$ & $\overline{\text { OR }}$ & $95 \% \mathrm{Cl}$ & $\overline{\text { OR }}$ & $95 \% \mathrm{Cl}$ & $\overline{\text { OR }}$ & $95 \% \mathrm{Cl}$ \\
\hline \multicolumn{11}{|c|}{ Pregnancy history: wanted (ref) } \\
\hline Mistimed & $0.67^{\star *}$ & 0.50 to 0.90 & $0.72^{* *}$ & 0.58 to 0.90 & 1.03 & 0.81 to 1.31 & $0.84^{*}$ & 0.73 to 0.97 & $0.75^{\star}$ & 0.60 to 0.94 \\
\hline Unwanted & 0.92 & 0.60 to 1.41 & $0.67^{\star}$ & 0.47 to 0.97 & 0.72 & 0.40 to 1.32 & 0.89 & 0.71 to 1.11 & 0.84 & 0.53 to 1.32 \\
\hline \multicolumn{11}{|c|}{ Maternal age: 15-19 (ref) (years) } \\
\hline $20-29$ & 0.61 & 0.36 to 1.05 & 0.84 & 0.51 to 1.40 & 0.80 & 0.46 to 1.38 & 0.96 & 0.51 to 1.83 & 0.72 & 0.33 to 1.59 \\
\hline 30-39 & $0.42^{*}$ & 0.21 to 0.83 & 0.61 & 0.34 to 1.11 & 0.88 & 0.46 to 1.66 & 1.17 & 0.61 to 2.25 & 0.92 & 0.40 to 2.10 \\
\hline $40-49$ & 0.47 & 0.19 to 1.14 & 0.74 & 0.36 to 1.52 & 1.16 & 0.56 to 2.43 & 1.76 & 0.87 to 3.55 & 1.35 & 0.55 to 3.34 \\
\hline \multicolumn{11}{|c|}{ Desire for more children: no more (ref) } \\
\hline Want more & $1.64^{\star \star}$ & 1.18 to 2.27 & $1.59^{\star \star \star}$ & 1.23 to 2.07 & $1.93^{\star \star *}$ & 1.45 to 2.57 & $1.44^{\star \star \star}$ & 1.22 to 1.71 & $1.84^{\star \star *}$ & 1.40 to 2.42 \\
\hline Parity & $1.20^{* * *}$ & 1.20 to 1.32 & 1.05 & 0.98 to 1.12 & 1.04 & 0.97 to 1.12 & $1.09^{\star * \star}$ & 1.04 to 1.14 & 1.04 & 0.97 to 1.12 \\
\hline \multicolumn{11}{|c|}{ Maternal education: higher (ref) } \\
\hline Secondary & 0.85 & 0.50 to 1.44 & 1.33 & 0.82 to 2.16 & $0.07^{\star *}$ & 0.01 to 0.41 & 1.90 & 0.95 to 3.79 & 0.85 & 0.37 to 1.93 \\
\hline Primary & 1.09 & 0.63 to 1.87 & $1.70^{*}$ & 1.04 to 2.78 & $0.08^{* *}$ & 0.01 to 0.47 & $2.41^{*}$ & 1.20 to 4.86 & 1.24 & 0.51 to 3.04 \\
\hline No education & 1.19 & 0.53 to 2.71 & $2.89^{* * *}$ & 1.60 to 5.22 & $0.10^{* *}$ & 0.02 to 0.58 & $2.73^{\star *}$ & 1.33 to 5.60 & 1.54 & 0.62 to 3.78 \\
\hline \multicolumn{11}{|c|}{ Wealth index: richest (ref) } \\
\hline Rich & 0.96 & 0.62 to 1.47 & 1.16 & 0.82 to 1.64 & 1.04 & 0.68 to 1.58 & 0.93 & 0.70 to 1.22 & 1.06 & 0.72 to 1.56 \\
\hline Middle & 0.94 & 0.59 to 1.47 & 1.45 & 0.97 to 2.17 & $1.77^{*}$ & 1.14 to 2.74 & 0.95 & 0.71 to 1.27 & 1.09 & 0.76 to 1.57 \\
\hline Poor & 0.99 & 0.61 to 1.62 & $1.60^{*}$ & 1.04 to 2.46 & 1.42 & 0.86 to 2.34 & 1.32 & 0.99 to 1.76 & 1.24 & 0.85 to 1.80 \\
\hline Poorest & $2.16^{\star \star}$ & 1.28 to 3.66 & $2.74^{\star \star \star}$ & 1.73 to 4.33 & $2.05^{\star \star}$ & 1.24 to 3.39 & $1.51^{\star \star}$ & 1.14 to 2.01 & $1.56^{*}$ & 1.06 to 2.31 \\
\hline \multicolumn{11}{|c|}{ Religion: Christian (ref) } \\
\hline Muslim & 1.56 & 0.96 to 2.54 & 1.24 & 0.87 to 1.77 & NA & NA & 0.71 & 0.37 to 1.37 & 0.85 & 0.50 to 1.45 \\
\hline Other & $2.82^{\star}$ & 1.18 to 6.74 & 2.10 & 0.80 to 5.53 & NA & NA & 0.75 & 0.43 to 1.28 & $0.51^{*}$ & 0.31 to 0.86 \\
\hline \multicolumn{11}{|c|}{ Listened to radio: yes (ref) } \\
\hline No & $1.35^{\star}$ & 1.03 to 1.77 & 1.12 & 0.87 to 1.45 & $1.38^{\star *}$ & 1.09 to 1.74 & $1.27^{\star \star \star}$ & 1.10 to 1.48 & 1.22 & 0.99 to 1.50 \\
\hline \multicolumn{11}{|c|}{ Watched TV: yes (ref) } \\
\hline No & 1.66 & 0.97 to 2.84 & 1.12 & 0.79 to 1.58 & 1.08 & 0.74 to 1.58 & 0.75 & 0.52 to 1.08 & $1.88^{*}$ & 1.11 to 3.18 \\
\hline \multicolumn{11}{|c|}{ Read newspaper: yes (ref) } \\
\hline No & 1.02 & 0.72 to 1.46 & 1.41 & 0.99 to 2.00 & 1.10 & 0.78 to 1.54 & 1.13 & 0.75 to 1.70 & 0.88 & 0.51 to 1.51 \\
\hline \multicolumn{11}{|c|}{ Healthcare decision-making: alone (ref) } \\
\hline Not alone & 1.02 & 0.77 to 1.36 & 1.02 & 0.80 to 1.31 & 1.06 & 0.77 to 1.45 & $1.33^{\star \star}$ & 1.11 to 1.58 & 0.84 & 0.59 to 1.20 \\
\hline \multicolumn{11}{|c|}{ Residence: urban (ref) } \\
\hline Rural & 1.35 & 0.89 to 2.06 & 1.07 & 0.77 to 1.51 & 0.86 & 0.63 to 1.18 & 0.94 & 0.68 to 1.31 & $1.53^{\star *}$ & 1.12 to 2.09 \\
\hline \multicolumn{11}{|c|}{ Visited by FP worker: yes (ref) } \\
\hline No & 0.95 & 0.63 to 1.43 & 1.17 & 0.86 to 1.59 & 1.16 & 0.74 to 1.85 & 1.13 & 0.98 to 1.31 & 1.26 & 0.85 to 1.87 \\
\hline \multicolumn{11}{|c|}{ Region (Kenya): Nairobi (ref) } \\
\hline Western & 0.69 & 0.40 to 1.17 & & & & & & & & \\
\hline Rift Valley & 1.20 & 0.73 to 1.98 & & & & & & & & \\
\hline Nyanza & 1.68 & 0.98 to 2.90 & & & & & & & & \\
\hline Eastern & 1.05 & 0.57 to 1.94 & & & & & & & & \\
\hline Coast & 1.02 & 0.62 to 1.69 & & & & & & & & \\
\hline
\end{tabular}




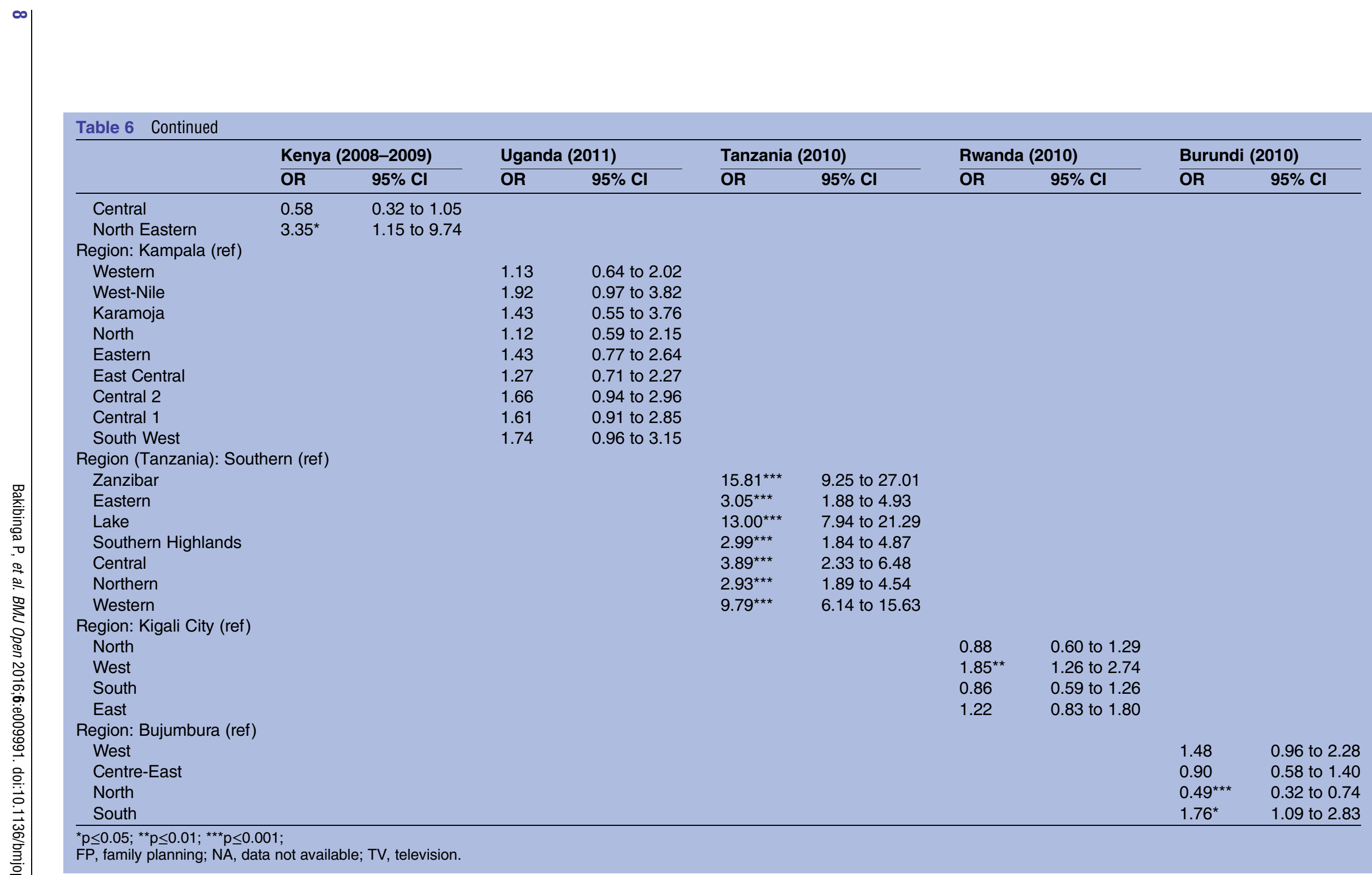


in the Nairobi region. In Tanzania, women sampled in Zanzibar, Lake and Western regions were over 10 times more likely (OR 15.81, 9.25 to 27.01, OR 13.00, 7.94 to 21.29 , OR $9.79,6.14$ to 15.63 , respectively) to use a nonmodern contraceptive method or none at all with the Southern region used as the reference. Women living in the Western region (OR 1.85, 1.26 to 2.74) of Rwanda were significantly different from those residing in Kigali city with the former having higher odds of engaging in sex using a non-modern contraceptive method or none. In Burundi, sexually active women in the Southern region (OR 1.76, 1.09 to 2.83) were two times more likely to report no/non-modern contraceptive use as compared to those sampled in the Bujumbura region.

\section{DISCUSSION}

This paper explored the relationship between women's pregnancy history and current use of contraceptives among women of reproductive age in the EAC region. Several control variables were included to examine the effect of pregnancy history on contraceptive use. The results indicate that women who had a mistimed pregnancy in their past were more likely to use a modern contraceptive method during their most recent sexual encounter in Kenya, Rwanda, Burundi and Uganda. This finding suggests that women's decision to adopt a modern contraceptive method was significantly influenced by their past birth histories and that those who had mistimed pregnancies were more keen to avoid future pregnancy. Similar relationships have been reported in the few studies that have investigated the relationship between a woman's pregnancy history and her contraceptive use patterns. ${ }^{16} 17$ Of significance to this finding is the study conducted in the urban slums of Kenya whereby unintended pregnancy history served as a 'wake-up call' and led to increased use of modern contraceptive methods. ${ }^{17}$

Other individual factors significantly associated with modern contraceptive use in our analysis were a woman's desire for more children and maternal parity. As expected, a woman who desired more children was less likely to use a modern contraceptive method than other women in all the East African countries studied. An increase in parity was also associated with a lack of modern contraceptive use in Kenya and Rwanda. This is significant given the fact that women who have more children are likely to have unplanned pregnancies as a result of not using a modern contraceptive in these two countries. These two results speak to the core of the high fertility rates noted in several East African countries. ${ }^{18}$ Importantly, it points to the major gaps in the use of contraception such as low access to FP services that could empower individuals to make informed choices with regard to use of contraception. ${ }^{1-4} 6$

The influence of household factors on contraceptive use is evidenced by the significance of household wealth, maternal education and media exposure through radio. Wealth, education and access to information inequalities were noted for women in the poorest household wealth quintile. Women with no education and those who could not access information through radio were more likely not to use modern contraceptive methods. This finding is in tandem with findings elsewhere that have documented the importance of socioeconomic status in influencing contraceptive use $\mathrm{s}^{23} 24$ and therefore cannot be underestimated. Poverty, lack of education and limited access to information are associated with higher fertility rates. It has been suggested that the effect of wealth, education and access to FP information on contraceptive use patterns could be through female autonomy and economic development. ${ }^{25} 26$ Socioeconomically empowered women are likely to afford modern contraceptive methods, make independent decisions on matters affecting their health and, most importantly, take advantage of the existing health services as evidenced in several studies. ${ }^{27-31}$

Controlling for individual, household and other community factors, this study noted substantial within-country differences in relation to contraceptive use. Apart from Uganda, other countries showed greater heterogeneity in their regions. For example, in Tanzania, sexually active women in Zanzibar, Lake and Western regions were over 10 times more likely to use non-modern contraceptives compared to women sampled in the Southern region. These significant differences within countries in the use of contraceptives could be a reflection of existing regional disparities in economic development, cultural orientation and may in part mirror inherent inequalities in the provision of health-related services across regions.

\section{Strengths and limitations}

A significant strength of this study is the use of nationally representative samples to study the influence of women's birth history on their contraceptive use in five East African countries. We also grouped possible predictor variables into distinct levels of analysis to study individual, household and community factors capable of influencing women's decision in contraceptive use.

A major limitation of this study is the failure to control for an important variable relating to decision-making on contraceptive use. Despite the availability of this variable in DHS data, there were many missing cases (as many as $60 \%$ of cases). Nonetheless, we used women's decisionmaking ability about their own health as a proxy for their autonomy in using contraception. We also did not take into account cultural variables in our regression equations. Lack of variables that could measure cultural influences in DHS data sets is a limitation, especially when studying behavioural practices that are highly influenced by cultural norms of the study populations. It is important to bear in mind that this study used crosssectional survey data, and therefore interpretations of findings in this study are limited to associations rather than causal relationships of the determinants of contraceptive use. 


\section{Conclusions and recommendations}

This study has demonstrated that women with a history of a previous mistimed pregnancy were more likely to be using a modern contraceptive in the East African region. Differences/variations in geographical residency, educational attainment, access to FP information and products, and wealth accumulation play a significant role in regard to FP access. These, among other differences and inequalities, should be addressed decisively as part of any upcoming strategic interventions to improve access to reproductive health services. Effective data collection, analysis and use for decision-making would be key in highlighting and addressing such differences and inequalities, thereby equitably expanding the health benefits of regional integration in the region as outlined in the 4th EAC Development Strategy. ${ }^{32}$

\section{Author affiliations}

${ }^{1}$ Health Challenges and Systems Research Program, African Population \& Health Research Center, Nairobi, Kenya

${ }^{2}$ Population Council, General Accident Insurance House, Nairobi, Kenya

${ }^{3}$ East African Community Secretariat, EAC Close, Arusha, Tanzania

${ }^{4}$ Department of Paediatrics and Child Health, College of Health Sciences, Makerere University, Kampala, Uganda

${ }^{5}$ Duke Global Health Institute, Durham, North Carolina, USA

${ }^{6}$ African Institute for Development Policy, Nairobi, Kenya

Acknowledgements The authors are grateful to the African Population and Health Research Center (APHRC): PAMANECH \& AHA projects for supporting our work. Further, we are grateful to Macro International Inc. for availing us the data sets.

Contributors PB conceptualised the study, participated in the interpretation of the data, managed the literature searches and wrote part of the first draft of the manuscript. DJM partly conceptualised the study, ran the statistical analysis and wrote part of the first draft of the manuscript. MA contributed in the analysis and writing of the manuscript. RA, JR, CM and DA contributed to the drafting of the manuscript. All authors read, reviewed and approved of the final manuscript.

Funding This study was made possible through the generous core funding to APHRC by the William \& Flora Hewlett Foundation and the Swedish International Development Agency (SIDA).

Competing interests None declared.

Provenance and peer review Not commissioned; externally peer reviewed.

Data sharing statement No additional data are available.

Open Access This is an Open Access article distributed in accordance with the Creative Commons Attribution Non Commercial (CC BY-NC 4.0) license, which permits others to distribute, remix, adapt, build upon this work noncommercially, and license their derivative works on different terms, provided the original work is properly cited and the use is non-commercial. See: http:// creativecommons.org/licenses/by-nc/4.0/

\section{REFERENCES}

1. NISR, Rwanda Demographic and Health Survey 2010, M.N.a.I. International, Editor. 2012, National Institute of Statistics of Rwanda (NISR), Ministry of Health (MOH) [Rwanda], and ICF International: Calverton, Maryland, USA.

2. KNBS, Kenya Demographic and Health Survey 2008-09, K.N.B.o.S. K.a.I. Macro, Editor. 2010, KNBS and ICF Macro Calverton, Maryland.

3. UBOS, Uganda Demographic and Health Survey 2011, U.a.I.I. Inc, Editor. 2011, Uganda Bureau of Statistics (UBOS) and ICF International Inc.: Kampala, Uganda and Calverton, Maryland, USA.
4. Institut de Statistiques et d'Études Économiques du Burundi (ISTEEBU)/Ministère des Finances et de la Planification du Développement Economique, a.t.I.N.d.S.P.I.M., Burundi 2010 DHS. Studies in Family Planning 2013;44(1):107-116.

5. Westoff CF. New Estimates of Unmet Need and the Demand for Family Planning. DHS Comparative Reports No. 14. Calverton, MD: Macro International Inc., 2006.

6. NBS, Tanzania Demographic and Health Survey 2010, N.B.o.S.N.T. a.I. Macro, Editor. 2011, National Bureau of Statistics (NBS) [Tanzania] and ICF Macro: Dar es Salaam, Tanzania.

7. EAC, Regional Strategic Plan On Sexual And Reproductive Health and Rights In East Africa: 2008-2013. 2007.

8. Gay E, Lee M. Reproductive health and economic well being in East Africa, P.a.P.R. Network, Editor. 2015, Population Reference Bureau. http://www.prb.org/pdf15/poppov-reprohealth-econ-eastafrica-brief.pdf

9. Bureau PR. 2012 World Population Data Sheet. 2012 [cited 2013 25.4.2013]. http://www.prb.org/Publications/Datasheets/2012/ world-population-data-sheet/fact-sheet-unmet-need.aspx

10. Rosenberg MJ, Waugh MS, Long S. Unintended pregnancies and use, misuse and discontinuation of oral contraceptives. J Reprod Med 1995:40:355-60

11. Hubacher D, Mavranezouli I, McGinn E. Unintended pregnancy in sub-Saharan Africa: magnitude of the problem and potential role of contraceptive implants to alleviate it. Contraception 2008;78:73-8.

12. Magadi MA. Unplanned childbearing in Kenya: the sociodemographic correlates and the extent of repeatability among women. Soc Sci Med 2003;56:167-78.

13. Tsui AO, McDonald-Mosley R, Burke AE. Family planning and the burden of unintended pregnancies. Epidemiol Rev 2010;32:152-74.

14. Kuroki LM, Allsworth JE, Redding CA, et al. Is a previous unplanned pregnancy a risk factor for a subsequent unplanned pregnancy? Am J Obstet Gynecol 2008;199:517.e1-7.

15. Matteson KA, Peipert JF, Allsworth J, et al. Unplanned pregnancy: does past experience influence the use of a contraceptive method? Obstet Gynecol 2006;107:121-7.

16. Orcutt HK, Cooper ML. The effects of pregnancy experience on contraceptive practice. J Youth Adolesc 1997;26:763-78.

17. Fotso JC, Izugbara C, Saliku T, et al. Unintended pregnancy and subsequent use of modern contraceptive among slum and non-slum women in Nairobi, Kenya. BMC Pregnancy Childbirth 2014;14:224.

18. East African Community (EAC), East African Community Facts and Figures-2014, EAC, Editor. 2014, EAC: Arusha.

19. Ross J, Winfrey W. Contraceptive use, intention to use and unmet need during the extended postpartum period. Int Fam Plan Perspect 2001;27:20-7.

20. Cleland J, Bernstein S, Ezeh A, et al. Family planning: the unfinished agenda. Lancet 2006;368:1810-27.

21. Cleland JG, Ndugwa RP, Zulu EM. Family planning in sub-Saharan Africa: progress or stagnation? Bull World Health Organ 2011:89:137-43.

22. Rutstein SO, Rojas G. Guide to DHS statistics. Calverton, MD: ORC Macro, 2006.

23. Agyei WK, Migadde M. Demographic and sociocultural factors influencing contraceptive use in Uganda. J Biosoc Sci 1995;27:47-60

24. Stephenson R, Baschieri A, Clements $S$, et al. Contextual influences on modern contraceptive use in sub-Saharan Africa. Am J Public Health 2007;97:1233-40.

25. Mutombo N, Bakibinga P. The effect of joint contraceptive decisions on the use of Injectables, Long-Acting and Permanent Methods (ILAPMs) among married female (15-49) contraceptive users in Zambia: a cross-sectional study. Reprod Health 2014:11:51.

26. Kravdal O. Education and fertility in sub-Saharan Africa: individual and community effects. Demography 2002;39:233-50.

27. Hameed W, Azmat SK, Ali M, et al. Women's empowerment and contraceptive use: the role of independent versus couples' decision-making, from a lower middle income country perspective. PLOS ONE 2014:9:e104633.

28. Gupta A, Roy TK, Sarker G, et al. Determinants of contraceptive practices among eligible couples of urban slum in Bankura District, West Bengal. J Family Med Prim Care 2014;3:388-92.

29. Achana FS, Bawah AA, Jackson EF, et al. Spatial and socio-demographic determinants of contraceptive use in the Upper East region of Ghana. Reprod Health 2015;12:29.

30. Bertrand JT, Sullivan TM, Knowles EA, et al. Contraceptive method skew and shifts in method mix in low- and middle-income countries. Int Perspect Sex Reprod Health 2014;40:144-53.

31. Egede JO, Onoh RC, Umeora OU, et al. Contraceptive prevalence and preference in a cohort of south-east Nigerian women. Patient Prefer Adherence 2015;9:707-14.

32. EAC, 4th EAC DEVELOPMENT STRATEGY (2011/12-2015/16): Deepening and Accelerating Integration. 2011. 